\title{
THE IMPACT OF THE AIR TEMPERATURE ON MEASURING THE ZENITH ANGLE DURING THE YEAR IN THE GROUND LAYER OF THE ATMOSPHERE FOR THE NEEDS OF ENGINEERING SURVEYING
}

\author{
Tomáš SUK*, Martin ŠTroner \\ Czech Technical University in Prague, Faculty of Civil Engineering, Department of Special Geodesy, \\ Thákurova 7, 16000 Prague, Czech Republic \\ * corresponding author: tomas.suk@fsv.cvut.cz
}

\begin{abstract}
This paper presents the results of over a year-long experiment dealing with a temperature measurement to calculate the theoretical effect of the atmosphere on the measured zenith angle in engineering surveying. The measurements were performed to determine the accurate and specific temperatures (temperature gradients), which can be recorded in different seasons in the low level of the atmosphere (up to $2 \mathrm{~m}$ above the ground, where most Engineering Surveying measurements take place) for the geographical area of Central Europe - specifically the Czech Republic. A numerical model was then applied to the resulting determined temperature gradients to calculate the path of the beam passing through an inhomogeneous atmosphere. From these values, the apparent vertical shifts caused by refraction in a given environment and time were finally determined.
\end{abstract}

KEYWORDS: Refraction, vertical temperature gradient, zenith angle, beam path, vertical shifts.

\section{INTRODUCTION}

Due to technical progress, geodetic instruments are constantly evolving and improving. For total stations, the standard deviation of the rangefinder is $1 \mathrm{~mm}$ (per $100 \mathrm{~m}$ ) and the accuracy of angles in units of tenths of a milligon is no exception (For example, as shown here [1-4]). Thanks to this, it is theoretically possible to carry out measurements with an accuracy of millimetres or, in special applications, even tenths of a millimetre. However, the condition for achieving these accuracies is not only the quality of the instrument used, or, in the case of adjustment, the number of redundant measurements, but also the suppression or elimination of errors caused by the surrounding environment. One of the environment influences, which has been studied in the geodesy for a long time, is atmospheric refraction - a set of atmospheric influences that negatively affects the measurement results.

In geodesy, according to [5], refraction can be divided into two basic groups according to the position of the observed target. On the one hand, astronomical refraction examines the influence of the atmosphere in the observation of celestial objects. Thus, it usually works with the assumption of the sight line close to vertical. Geodetic refraction, on the other hand, describes the influences acting on ground targets (in common geodetic practice on the Earth's surface). Geodetic refraction can then be divided according to which direction it affects in terms of a measurement. So, we are talking about vertical or horizontal refraction. In the following, text we will deal with the vertical refraction in a specific application of engineering surveying (ES) in the low level of the atmosphere (to $2 \mathrm{~m}$ above the ground) affecting the zenith angle. We will not pay more attention to other types here.

Attempts to suppress or eliminate the influence of refraction date back a very long time, and many theories and experiments have been made on this topic over the past century. Some older works, focused on trigonometric measurements in mountain areas, taking into account the effect of refraction, were carried out in the 60 s and 70 s by Mr. Hradílek (for example, 6] and [7). This research is still relevant, as evidenced, for example, in publication [8]. Another interesting article describes the effect of refraction on geodetic measurements in another medium - water [9]. In principle, this effort can be divided into several basic variants.

The first variant is, of course, the use of direct geodetic measurements to detect refraction. This is most often a counter-measurement of zenith angles or a calculation of $k$, as a variable, within a given trigonometric network [10]. An interesting and innovative way of measuring opposite zenith angles is described, for example, in [11].

Another way is to apply atmospheric models to the measured data. One of the most famous is the creation of the temperature equation from Kukkamaki 12, which was used for precise levelling. There are several parameter adjustments for different areas and use 13. Currently, it is very common to determine the computer model by the reverse method, where the measured data derive theoretical relationships (polynomial and other functions) between the measured quantities defining the state of the atmosphere and the measured geodetic data [14, 15]. In this case, we encounter the problem that derived re- 
lationships are often only theoretical and cannot be applied, in general, across seasons and parts of the world.

Another approach is to determine the current turbulent parameters of the well-known Monin - Obukhov similarity theory (described in [16] and [17]). To calculate the refractive index, it is important to determine the turbulent parameters $C$ and $l$, for which it is possible to use scintillometry and/or Image dancing method 18 20]. Monin - Obukhov method has its limits in the assumptions of the uniform stratification of the atmosphere (although there are modifications [18]) and especially in the use of the coefficient $k$ or temperature gradient describing the whole path of the beam, or the whole set of measurements. At present, this method is already considered insufficient.

The list of possibilities is followed by a technologically very complex dispersion method (described in [19, 20]), which is based on the transmission of a pair of beams of different wavelengths (most often IR and blue), which bend slightly differently as they pass through the atmosphere. It is, therefore, possible to measure the difference between the points (angle) of impact. From this, it is possible to derive the refractive coefficient or the effect of the refraction as such. This method is difficult due to the necessity of measuring a very small difference between the points (angles) of impact of individual colours with sufficient accuracy 21].

The path used in this article differs from the methods described. By monitoring the physical properties of the atmosphere (specifically its temperature and temperature gradient), the current state is described, for which a mathematical simulation of the beam's passage through an inhomogeneous medium is performed (measurement simulation) using the numerical model. The basis of this calculation is the knowledge of the refractive index of air and its gradient. The refractive index depends mainly on temperature and pressure. At short distances (as in ES) the pressure practically does not change (does not affect the gradient). The main influence is the temperature gradient, which is determined by a system of temperature sensors placed on a vertical structure designed for experimental purposes. In the past, this approach has already been attempted, but with significantly worse technical equipment (e.g. Sirǔčková [22] and others) and especially with the effort to introduce corrections to actual measurements. In our case, there is an effort to know the properties and laws of the phenomenon in the ground layer of the atmosphere and to make basic recommendations for the practical measurement.

For the purpose of estimating the real state of the atmosphere, an extensive series of all-day experiments were measured for over a year with an interval of about 15 to 20 days. Through the set of data from each day, several simulations were done (more described below). The result of the simulation is a theoretical estimate of the effect of the atmospheric refraction on the zenith angle (observed point height) for a given situation.

\section{EQUIPMENT AND EXPERIMENT}

The first part of this chapter provides a basic overview of the apparatus and equipment used to carry out the temperature (temperature gradient) measurement, followed by a simple analysis of the accuracy of the whole system. The second subchapter describes the experiment and basic output measurements. In the last part, the used numerical model and the main partial calculations are explained and formulated.

\subsection{Equipment}

For the implementation of experiments of a temperature measurement, a measuring apparatus was designed and assembled, consisting of a set of resistance temperature detectors (RTDs), a data logger and a shielding and supporting structure.

\subsubsection{Resistance temperature DeteCtor}

The determination of temperature by RTDs uses a known physical principle describing the dependence of the change in resistance of a conductor on the change in its temperature. In this case, the opposite view is used, where a change of the resistance is observed and the change in temperature is derived from it.

TR097C sensors manufactured by SENSIT s.r.o. were used for most of the measurements. (For some measurements, the TG8-40 sensor, which is a similar type with the same accuracy, was also used). TR097C is equipped with a calibrated platinum sensor (Pt1000 ( 3850 class A). The detector technically consists of a lacquer encapsulated sensor to increase physical resistance, a supply cable in a protective insulating silicone sleeve and an insulated connector to the data logger. The disadvantage of this sensor is a lower physical resistance and a lower resistance to moisture and other weather conditions.

The permitted deviation $\Delta T_{S}$ for platinum sensors class can be determined as:

$$
\Delta T_{S}=(0.15+0.002 \cdot|t|),
$$

where $|t|$ is the temperature in an absolute value. In the range of measured values (approx. -20 to $40^{\circ} \mathrm{C}$ ), the permitted deviation $\Delta T_{S}$ is approx. 0.15 to $0.25^{\circ} \mathrm{C}$ [23, 24].

\subsubsection{DATAlogGer}

The data logger S 0141 (Fig. 1, manufactured by Comet System s.r.o.) enables temperature calculation (transition from resistance to temperature measurement) and subsequent registration. The logger is equipped with four inputs for sensors, a smaller black and white display and an input for connecting a communication cable to a PC (in the form of USB, COM or WIFI). The control and settings are changed via the computer program Comet Vision provided by the manufacturer. 


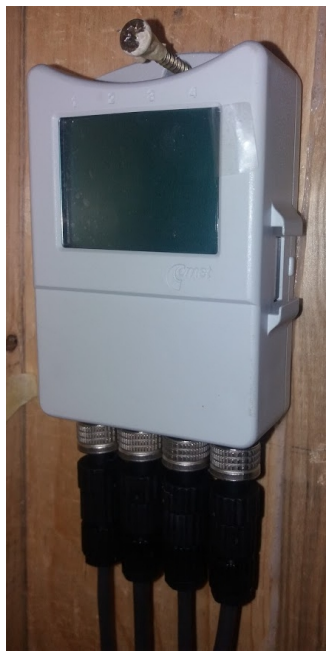

Figure 1. Datalogger S0141.

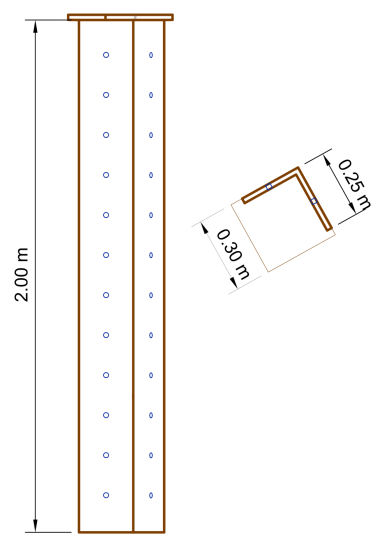

Figure 2. Construction - layout.

The data logger has a defined measuring temperature range from $-90^{\circ} \mathrm{C}$ to $260^{\circ} \mathrm{C}$ for the Pt1000 sensor used. For temperatures measured during the experiment, a margin of the permitted deviation $\Delta T_{L}$ equals to approximately $0.2^{\circ} \mathrm{C}[24$.

\subsubsection{SHIELDING AND SUPPORTING STRUCTURE}

For the purposes of shading out sunlight and heating prevention, sensors were installed in a wooden structure, which also serves as a supporting element of the apparatus. At the same time, the construction prevents thermal radiation of other (more thermally conductive) objects.

For this purpose, a simple L-shaped cover system (see Fig. 2) has been designed with regularly drilled holes (to allow air to pass through), which are tilted downwards.

\subsubsection{Analysis of THE ACCURACY OF TEMPERATURE MEASUREMENT OF THE WHOLE SYSTEM}

From the above permitted deviations $\Delta T_{L}$ and $\Delta T_{S}$, the standard deviations of the logger $\sigma_{L}$ and the sensor $\sigma_{S}$ can be calculated using the law of standard deviation transmission

$$
\begin{aligned}
\sigma_{S} & =\frac{\Delta T_{S}}{2}=\operatorname{approx} .0 .10^{\circ} \mathrm{C} \text { to } 0.13{ }^{\circ} \mathrm{C}, \\
\sigma_{L} & =\frac{\Delta T_{L}}{2}=0.10^{\circ} \mathrm{C}
\end{aligned}
$$

where $\Delta T_{L}$ a $\Delta T_{s}$ are the permitted deviations in the temperature range for the logger and the sensor. Subsequently, the accuracy of the determined temperature $\sigma_{T}$ can be derived as

$$
\sigma_{T}=\sqrt{\sigma_{S}^{2}+\sigma_{L}^{2}}=0.15^{\circ} \mathrm{C} .
$$

The resulting accuracy of the temperature determination is thus $\sigma_{T}=0.14$ to $0.16{ }^{\circ} \mathrm{C}$ in a given temperature range. In further analyses, we will consider $\sigma_{T}=0.15^{\circ} \mathrm{C}$, which also corresponds to a long-term observation.

Since the standard deviation of the temperature determination can be considered as the same for every sensor, we can calculate the standard deviation of the temperature difference $\sigma_{\Delta T}$ according to

$$
\sigma_{\Delta T}=\sigma_{T} \cdot \sqrt{2}=0.21^{\circ} \mathrm{C}
$$

with the permitted deviations $\Delta M_{T}=0.42^{\circ} \mathrm{C}$. For the temperature gradient, the standard deviation $\sigma_{\nabla T}$ is determined as

$$
\sigma_{\nabla T}=\frac{\sigma_{\Delta T}}{d H}
$$

where $d H$ is the vertical distance between the sensors. After substituting into the equation, we get the results given in Tab. 1 .

\subsection{EXPERIMENT}

The measuring experiment was carried out in order to determine the actual prevailing conditions on the ground level of the atmosphere in the Czech Republic. The measured data are available from professional meteorological stations, but they usually describe the parameters at a certain height and do not reach such accuracy and frequency, which is necessary for a reliable determination of the temperature gradient. Therefore, an apparatus was assembled (see Chapter 2.1.3), which allows a simultaneous temperature measurement at four different heights above the surface. Subsequently, it is possible to determine temperature gradients.

In terms of the time schedule, it was decided on a continuous measurement of at least 24 hours and a recording interval of $20 \mathrm{~s}$. The interval between individual days of measurement was chosen to be about 15 to 20 days (depending on the weather). The result is 23 days of measurements distributed throughout the year, which map the development of temperature across the seasons. All measurements were recorded in Central European Time CET (UTC +01:00). 


\begin{tabular}{lccc}
\hline gradient vertical range $\Delta T$ & $(0.5-1.0 \mathrm{~m})$ & $(1.0-1.5 \mathrm{~m})$ & $(1.5-1.9 \mathrm{~m})$ \\
\hline$\sigma_{\nabla T}\left[{ }^{\circ} \mathrm{C} / \mathrm{m}\right]$ & 0.42 & 0.42 & 0.53 \\
\hline
\end{tabular}

TABLE 1. Accuracy of temperature gradients.

\subsubsection{Measurement Results}

The measurement was performed on a regularly mown lawn. Except for the data from 1.4.2020 to 20.5.2020, the structure was in the shade most of the day. In the mentioned interval, it was measured in a sunny area with all-day sunlight.

An example of typical data measured on a sunny day is the measurement from 7.5.2020 (shown in Fig. 3 and Fig. 4). The first graph shows the development of temperature at given heights. We can notice a significant fluctuation in temperature in the afternoon and a relatively calm, although stratified atmosphere in the night.

Fig. 4 shows the development of the vertical temperature gradient during the day 7.5.2020. The results confirm the often-described phenomenon that during the day (sunny), the earth's surface heats up and the temperature gradient becomes negative (in this case also at a height of 0.50 to $1.00 \mathrm{~m}$ !). At a height of 1.00 to $1.50 \mathrm{~m}$, the gradient is relatively small, as the temperature radiated by the surface and the temperature of the higher layer are "equalized" (warmer air rises). The top layer reaches high gradients (some other experiments confirmed a positive temperature gradient up to 4 meters above the ground).

It is necessary to repeat here that the data describe a specific sunny day with the measuring equipment placed on a sunlit lawn during the whole day. Other days, such as when the apparatus was in a shade, the graphs would look relatively different in the illustration. Unfortunately, due to the scale, they will not be included here.

\subsubsection{Determination of temperature GRADIENT}

Due to the large volume of data, the vertical temperature gradient $\nabla_{t}$ was calculated only for specific times of each day. These times are 00:00, 4:00, 8:00, 12:00, 16:00 and 20:00. In order to make the calculation of the gradient more reliable from the point of view of defining the season, a regression function (2nd order polynomial) was calculated from the measurements in the period -30 to +30 min and a specific functional value of this polynomial was used in the following calculation.

The following Fig. 5 and Fig. 6 show gradients for selected times during each day. The dotted line shows the gradient for the lower section $(0.5$ to $1.0 \mathrm{~m})$, the dashed line for the middle section $(1.0$ to $1.5 \mathrm{~m})$ and the solid line for the upper section ( 1.5 to $1.9 \mathrm{~m}$ ). It is clear that the resulting gradients can take on high values exceeding $4.5^{\circ} \mathrm{C} / \mathrm{m}$. The most significant gradients are in a sunny place during the measurement (1.4.2020 to 20.5.2020).

Since the temperature gradient used is obtained by a regression function from a relatively large number of measurements, its accuracy can be expected to be higher than that of the calculated in the accuracy analyses (Chapter 2.1.4). However, the standard deviation of the average cannot be used due to the influence of systematic errors burdening the measured set.

\subsection{Calculations}

Fig. 7]shows, in a simplified manner, the relationships between significant parameters defining the vertical refraction and its influence on the measured values. Between points $A$ and $B$, the slope distance $s d$ and the zenith angle $z_{A}$ are marked. The points are located on the earth's surface (represented by a sphere of radius $R$ and centre $S$ ) at height $H_{A}$ (respectively $H_{B}$ ). The distance of the points along the circle $S_{H_{A}}$ at the height $H_{A}$ defines the central angle $\varphi$.

Furthermore, the apparent point $B^{\prime}$ shifted to from the actual position by the vertical error $\Delta H_{B}$ is marked. The error is caused by the angular deviation of the beam from the straight trajectory - refractive angle $\beta / 2$ (if the refractive curve is not circular, then this angle is general $\rho_{A}$ ), or more precisely the tangent $t_{A}$ to the substitute circular refractive curve (purple) at point $A$. The refractive curve is defined by centre $D$, radius of curvature $R_{k}$ and centre angle $\beta$, which is also referred to as the angle of complete refraction. The zenith angle $z_{A}^{\prime}$ describes the value that we would actually measure [5].

\subsection{Differential EQUATION OF THE PASSAGE OF A WAVE-PATH}

Above the measured data, specifically above the obtained gradients, a simulation of the beam passage by the DEPWP method (differential equation of the passage of a wave-path through inhomogeneous atmosphere) was performed. It is a physical relationship describing the change of the direction of the beam dependent on the refractive index and the change (gradient) of the refractive index of the given environment (derived in 25]). The whole relation according to [26] and 27] can be written as

$$
\frac{d^{2} r}{d t^{2}}=n(r) \cdot \nabla n(r)=f(r)
$$




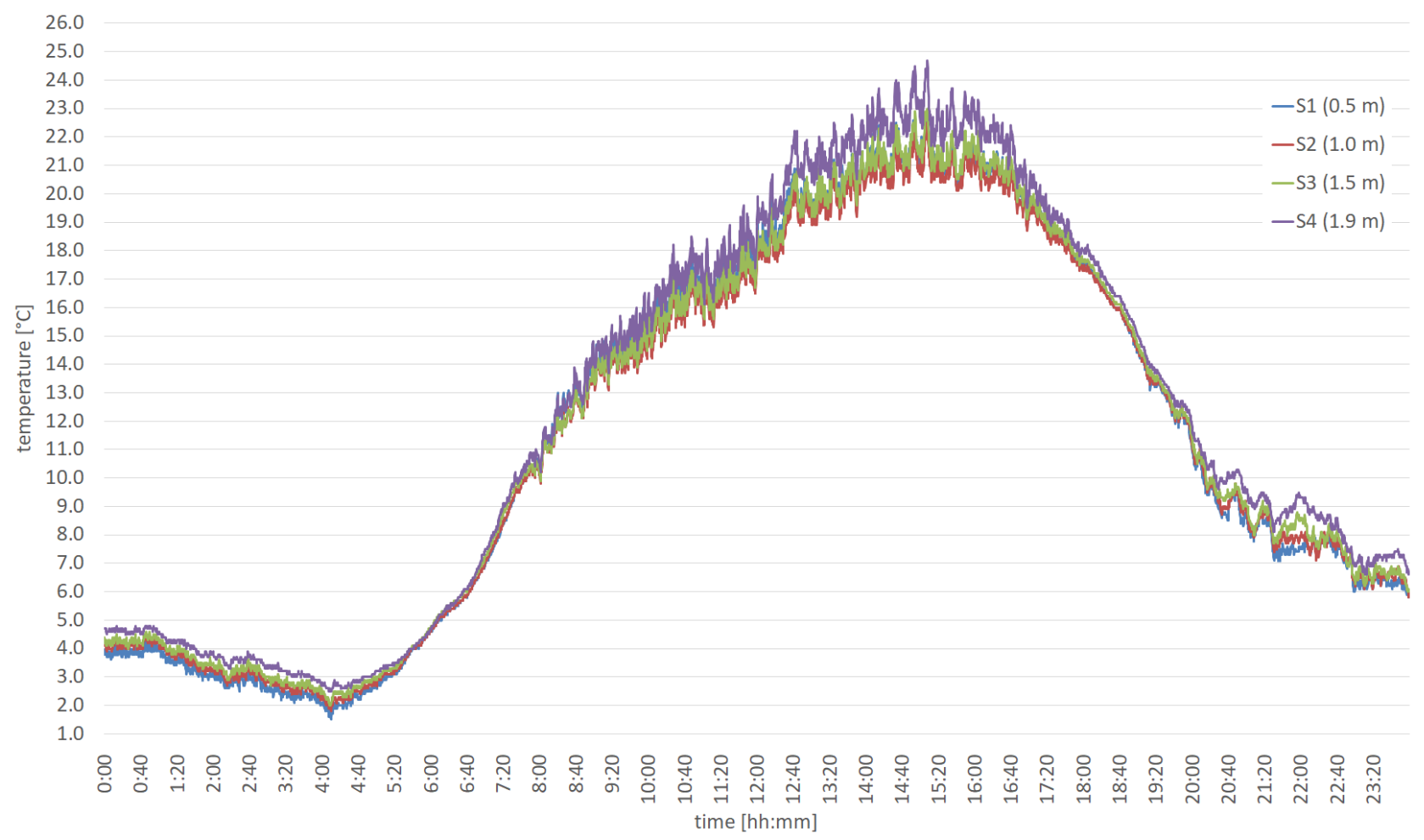

FiguRE 3. Development of temperature during the day 7.5.2020.

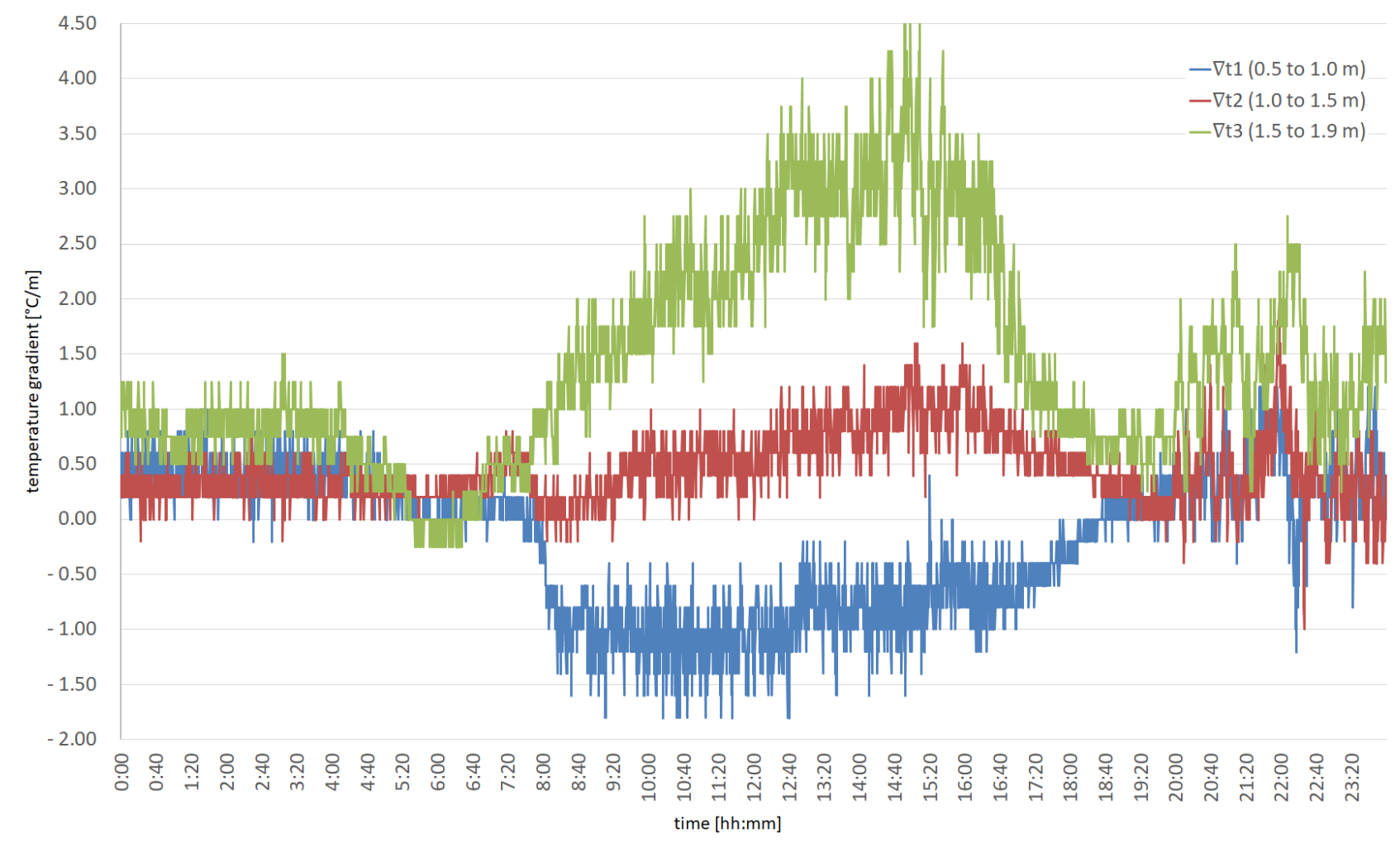

Figure 4. Development of temperature gradient during the day 7.5.2020. 


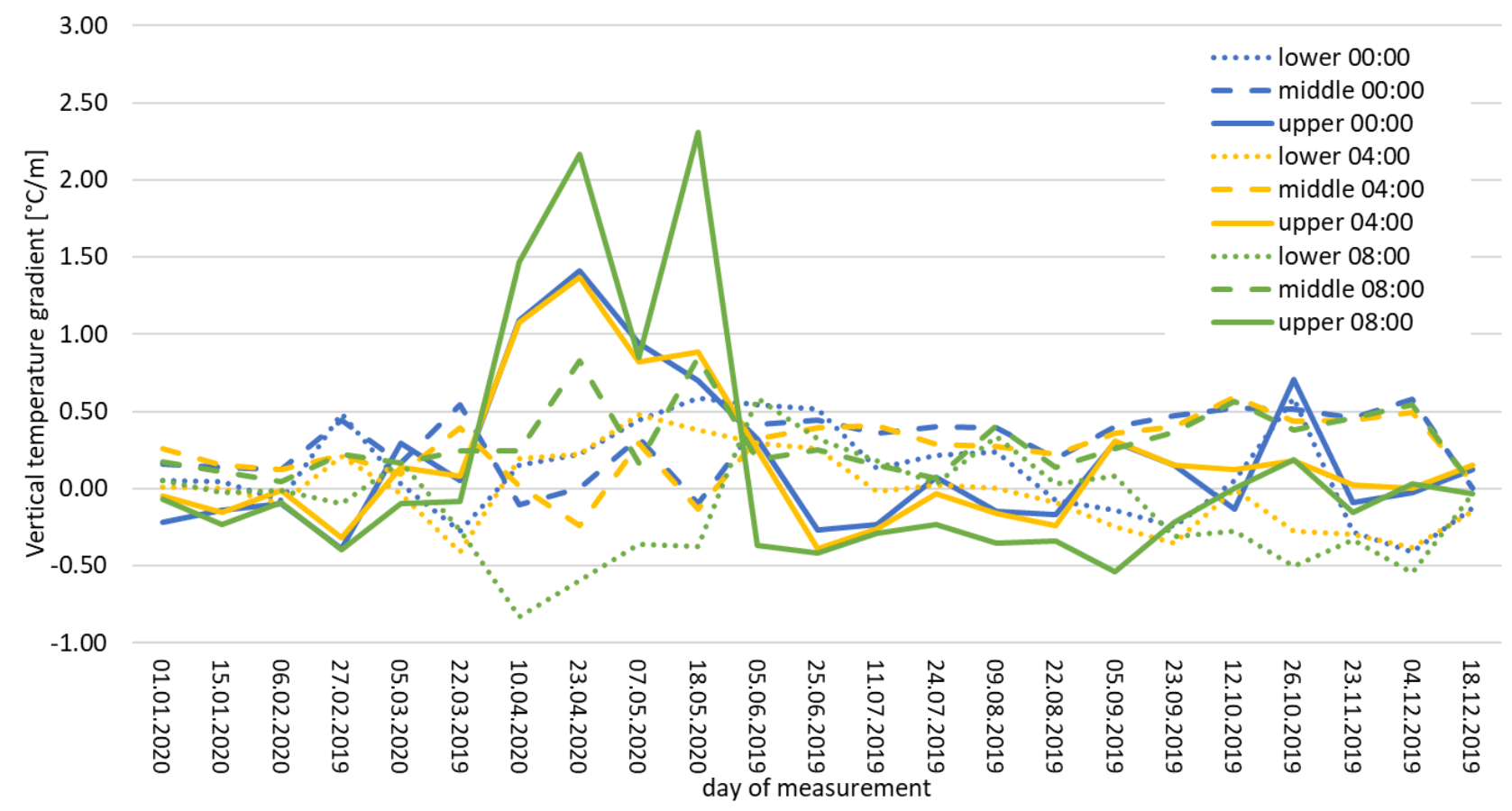

FIGURE 5. Interpolated temperature gradients for times 0:00, 4:00 and 8:00.

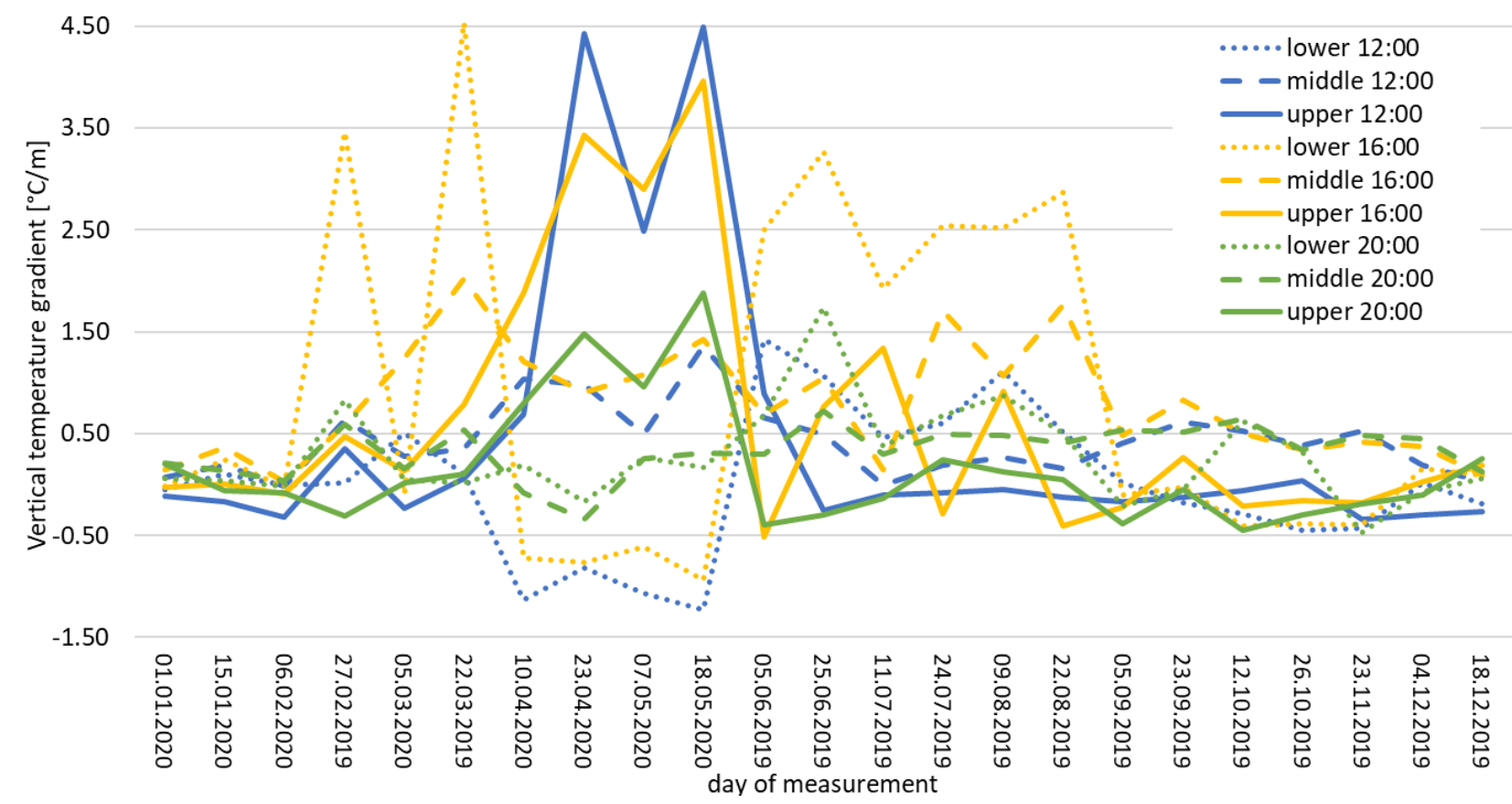

FIGURE 6. Interpolated temperature gradients for times 12:00, 16:00 and 20:00. 


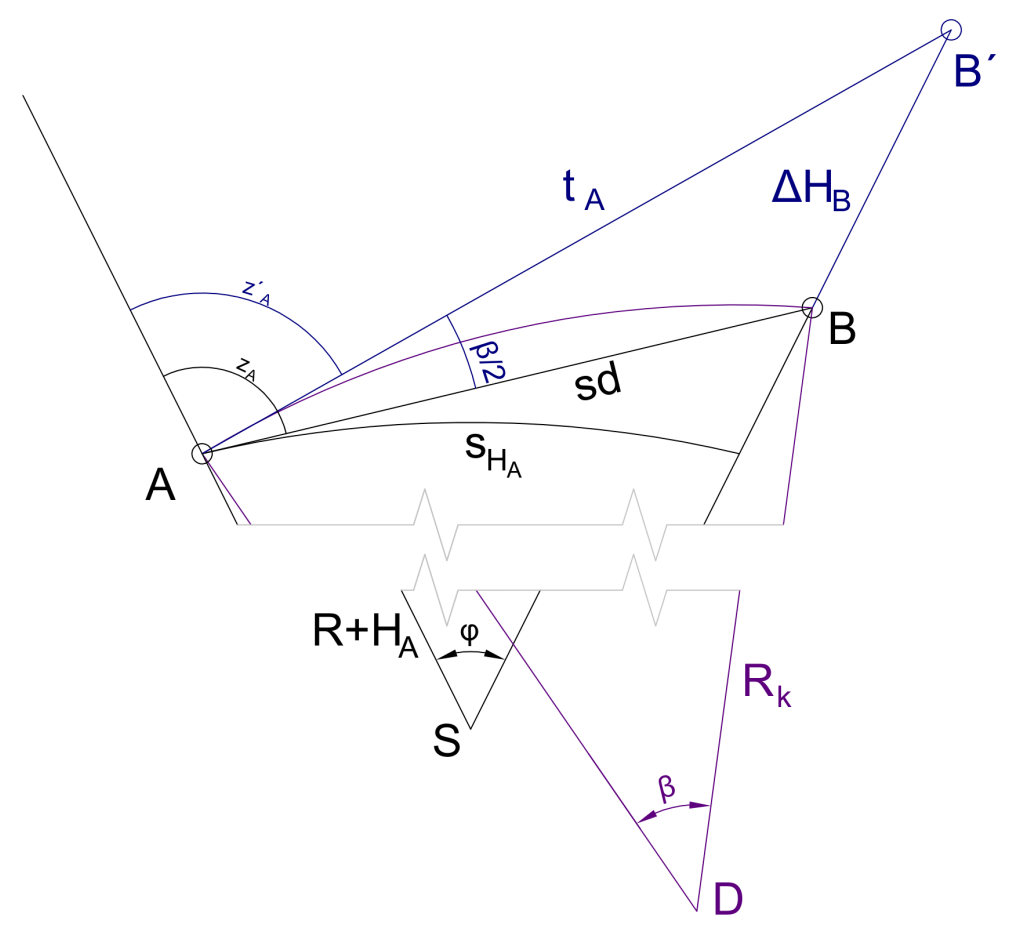

FiguRE 7. Relationships between measured and determined quantities.

$$
\begin{aligned}
& r=\left(\begin{array}{l}
x \\
y \\
z
\end{array}\right), \\
& n(r)=n(x, y, z), \\
& \nabla n(r)=\left(\begin{array}{c}
d n(r) / d x \\
d n(r) / d y \\
d n(r) / d z
\end{array}\right),
\end{aligned}
$$

where vector $r$ defines a specific point on the beam path and is expressed in coordinates, $n$ is the refractive index of the medium and $\nabla n$ is the gradient of the refractive index in the directions of the coordinate axes.

The calculation is performed numerically, and a designation can be introduced for a better understanding

$$
u=\frac{d r}{d t}, \quad \frac{d u}{d t}=\frac{d^{2} r}{d t^{2}}
$$

where $u$ is the direction vector and $d t$ is a differential part of the path [27].

We can convert this second order differential equation (8) to two differential equations of the first order and then solve them simultaneously.

$$
\frac{d u}{d t}=f(r), \quad \frac{d r}{d t}=u,
$$

The initial conditions are position $r_{0}$ (Total station) and direction $u_{0}$ (to the measured point - zenith angle). Using a sufficiently small step $d t \rightarrow \Delta t$ (in our case $\Delta t=0.1 \mathrm{~mm}$ ) we can calculate the numerical passage through the atmosphere. The resulting equations for the numerical pass are as follows:

$$
\begin{array}{r}
d r_{i+1}=u_{i} \cdot \Delta t, \quad r_{i+1}=r_{i}+d r_{i+1}, \\
d u_{i+1}=f\left(r_{i+1}\right) \cdot \Delta t, \quad u_{i+1}=u_{i}+d u_{i+1}
\end{array}
$$

\subsubsection{BARREL-SEARS FORMULA}

The Barrel-Sears formula with temperature and pressure correction can be used to calculate the refractive index of air [28]. Although more accurate procedures are available [29], these formulas are sufficiently accurate for this purpose.

$$
\begin{aligned}
N= & 287.604+\left(\frac{1.6288}{\lambda^{2}}\right)+\left(\frac{0.0136}{\lambda^{4}}\right), \\
n=1+ & \left(\left(\frac{N}{1+\frac{t}{273.15}}\right) \cdot \frac{p}{101325}-\right. \\
& \left.-\left(\frac{5.5 \cdot 10^{-2}}{1+\frac{t}{273.15}}\right) \cdot \frac{h}{133.322}\right) \cdot 10^{-6},
\end{aligned}
$$

where $\lambda$ is the wavelength of radiation in $\mu \mathrm{m}, t$ is the temperature, $p$ is the pressure and $h$ is the partial pressure of water vapour.

For the calculation of the models, visible light of $\lambda=$ $0.555 \mu \mathrm{m}$, and water vapour pressure $p=101325 \mathrm{~Pa}$ and water vapour pressure $h=0 \mathrm{~Pa}$ were considered. In essence, the effect of the change in pressure and water vapour pressure was not taken into account.

\subsubsection{Iterative CALCULATION OF PATH}

After calculating the gradients, the iterative simulation of the beam path according to DEPWP was performed. Thus, the calculation of the apparent vertical displacement $\Delta H$ - the height deviation of the actual path from the straight line, was realised. Three 
paths of the beam were calculated with the specified distance $s=50 \mathrm{~m}$ and with a variable zenith angle $\left(z_{0}=99.2,100.0\right.$ and 101.2 gon $)$. The vertical shift $\Delta H$ is, therefore, a function of these variables

$$
\Delta H=D E P W P\left(\nabla T_{i}, s, z_{0}, \ldots\right) .
$$

From the obtained vertical shift, the first iteration of the "refractive angle" $\rho_{1}$ at survey station was calculated backwards. The following simplification also applies to $z \approx 100$ gon

$$
\begin{gathered}
\rho_{1}=\frac{\sin (z) \cdot \Delta H}{s / \sin (z)-(\cos (z) \cdot \Delta H)} \approx \frac{\Delta H}{s} . \\
z_{1}=z_{0}+\rho_{1}
\end{gathered}
$$

The newly determined zenith angle $z_{1}$ is obtained by adjusting the initial zenith angle $z_{0}$ by the refractive index. Usually, in the second or third iteration, the beam strikes the target with an accuracy of more than $0.001 \mathrm{~mm}$. By this procedure, the resulting refractive angle $\overline{\rho_{1}}$, and the resulting vertical displacement of the target $\overline{\Delta H}$ was determined according to

$$
\overline{\rho_{1}}=z_{n}-z_{0}, \quad \overline{\Delta H} \approx \overline{\rho_{1}} \cdot \frac{s}{\sin \left(z_{0}\right)} .
$$

\section{Results}

The very determination of real temperatures (see example Fig. 3 prevailing during the year in the microclimate of the ground level of the atmosphere can be considered as a result of the experiment itself. This research has not been carried out in our territory so far, and in previous refraction solutions, estimates or data determined elsewhere were used. Of course, it is not possible to use the specified temperatures as generally applicable, as they are influenced by the whole spectrum of parameters, such as position, influence of surrounding objects, material of the surface, content of dust particles. Nevertheless, the data are important for obtaining a qualified estimate of possible temperatures in our conditions. Equally important is the determination of the temperature gradients shown in Fig. 4

\subsection{VERTICAL SHIFTS}

Using the DEPWP simulation described in Chapters 2.4 to 2.4 .2 the values of the vertical shifts (difference between the apparent and the actual target) for each beam path can be obtained. For better clarity, the results are again displayed for selected times of day (00:00, 4:00, 8:00, 12:00, 16:00 and 20:00) in the form of graphs (see Fig. 8), which describe the vertical shifts (corrections) for $z=99.2 ; 100$ a 101.8 gon. This range of the zenith angle was chosen due to the use of the entire height of the measuring structure (up to $2 \mathrm{~m})$.

It is clear from the graphs that the direct exposure of the terrain greatly affects the vertical change (the largest ones were calculated for the days when the structure was placed in a sunny position). Furthermore, it is worth recalling that the calculated deviations in some days and times are essential for many geodetic applications and it is necessary to consider them or change the principle or the time of the measurement accordingly. The highest deviations are usually achieved in the afternoon, when, in the summer months, the error exceeding $2 \mathrm{~mm}$ is not uncommon. On the contrary, the lowest error is observed early in the morning and later at night, when it usually does not exceed $1 \mathrm{~mm}$.

\section{REAL BEAM TRAJECTORY}

For a better idea of the realization of the actual trajectory, graphs in Fig. 9 to Fig. 11 show the beam trajectory on selected days. The straight line is shown in black and the differences in the trajectory from the straight line at a particular point are multiplied by 1000 for better clarity (so they are in $\mathrm{mm}$ ).

The graphs show all three variants of zenith angles at once and the individual paths according to the time of day are shown by a coloured dashed line chosen according to Tab. 2

Note that in Fig. 9, the beam trajectory is flat and very close to a straight line. For $z=99.2$ gon, the curve is convex towards the surface, while for the others, it is inverted. This is due to a negative gradient in the higher part of the measured range.

The graph Fig. 10 shows a state where the apparatus has been placed in a sunny place. The gradients are very high and vertical deviations are as well. Importantly, for $z=99.2$ and 100 gon, the curve is always concave, while for $z=101.8$ gon, it is convex during the day (8:00 to 16:00) and concave at night. This is due to the large thermal radiation of the surface.

In the last measurement shown (see Fig. 11), from the end of October, the curves are relatively flat, but the state is very variable. For $z=99.2$ gon, it is concave in the morning, almost straight at noon and convex in the afternoon. With a horizontal view of $z=100$ gon, the curve is always concave and for $z=102.8$ gon, the curve is concave at night (0:00 and 20:00) and convex during the day due to the thermal radiation of the surface.

\section{Discussion}

The main benefit of this experiment and article should be a warning about refraction, or rather that the solution of its influence is no longer just a question of academia and the construction of large point fields. On the contrary, the current direction of accurate geodesy directly requires a practical investigation of the impact of refraction and the active minimization of its influence on geodetic data. After all, as the results published here shows, it is still true that for applications, where accuracy in the order of centimetres is required, refraction is not critical and will not need to be addressed. However, in areas where an 


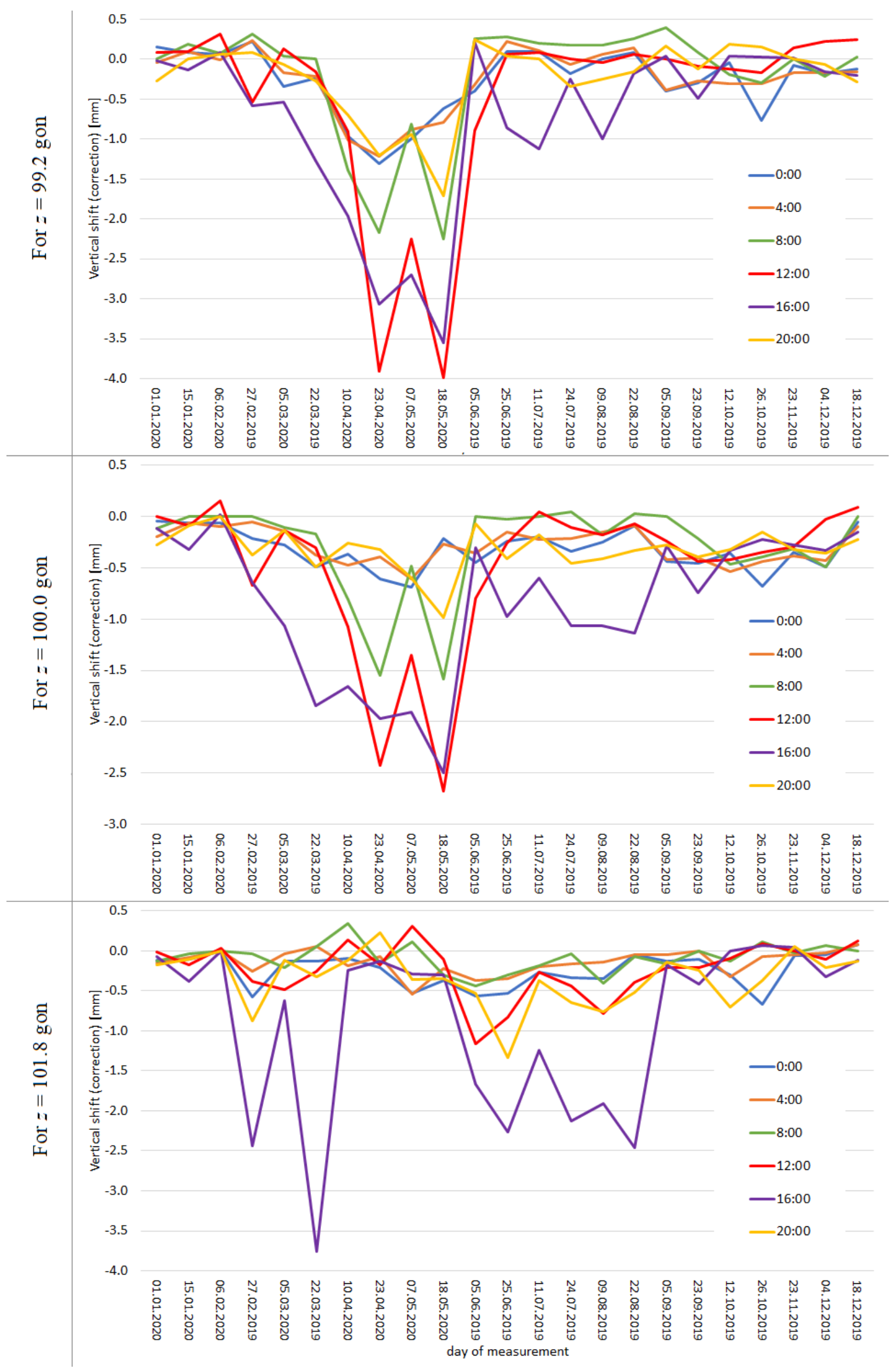

Figure 8. Vertical shifts for $z=99.2 ; 100.0$ a 101.8 gon. 


\begin{tabular}{lcccccccc}
\hline Trajectory & straight & $0: 00$ & $4: 00$ & $8: 00$ & $12: 00$ & $16: 00$ & $20: 00$ \\
Color & & & & & & & & \\
\hline
\end{tabular}

TABLE 2. Colors of individual paths.

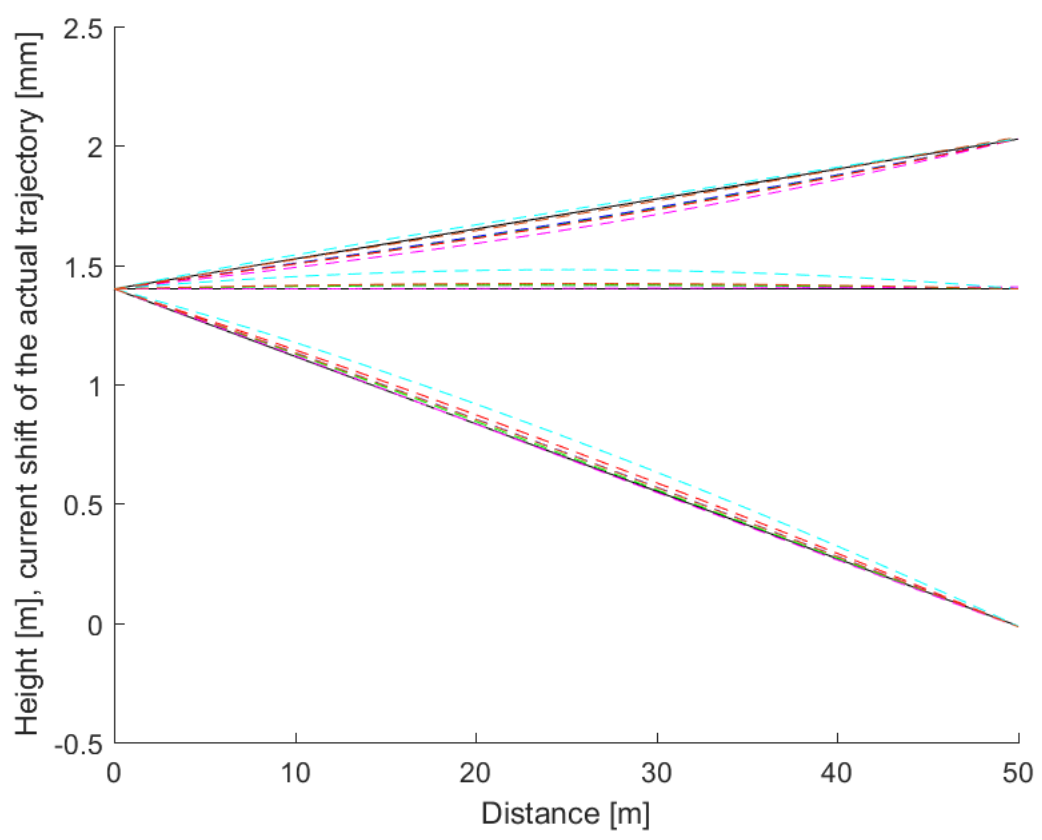

FiguRE 9. The real trajectory of the beam of the day 15.1.2020.

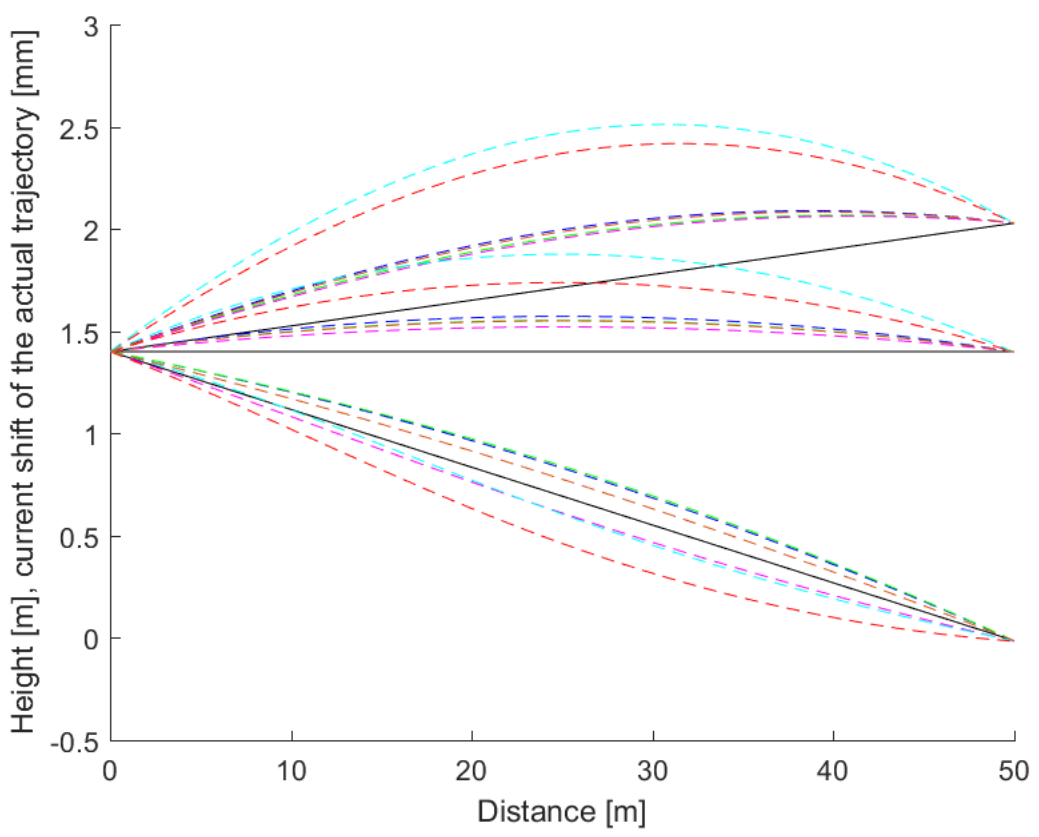

FiguRE 10. The real trajectory of the beam of the day 7.5.2020. 


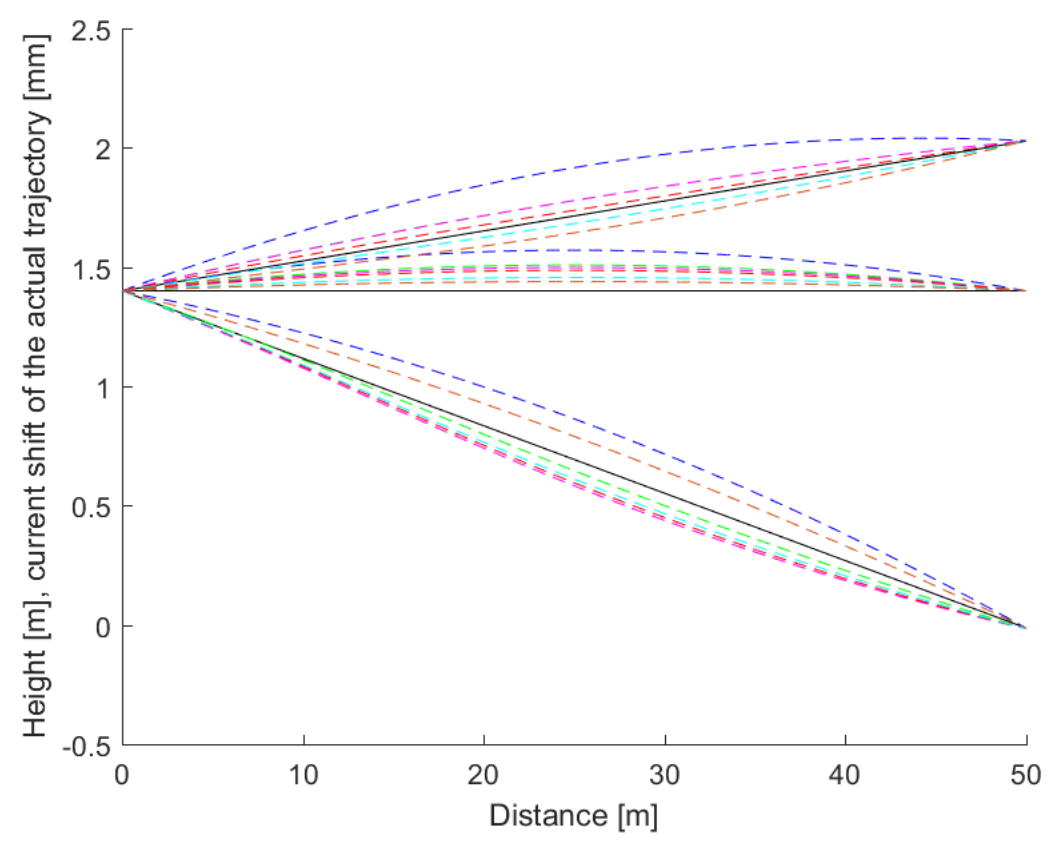

FiguRE 11. The real trajectory of the beam of the day 26.10.2019.

accuracy of more than one $\mathrm{cm}$ is required, it will be necessary to consider the possible impact of refraction and its possible suppression. If we focus on specialized geodetic work in construction, engineering or control measurements, then the accuracy is in units of millimetres and refraction can easily become a significant systematic component of measurement errors

The results also clearly show that the atmosphere is very variable and cannot simply be described by a single universal number, as the Gaussian refractive index $k=0.1306$ is sometimes incorrectly presented. This number describes the atmosphere in a particular area, which is very far from the application of engineering surveying. T. Křemen deals, in detail, with the issue of the Gaussian coefficient in article [10. The theoretical refractive index can be calculated retrospectively from the determined vertical displacements. The measured data show that the coefficient usually takes values up to +3 and seldomly takes negative values. For measurements in a sunny place, it even reaches values exceeding +20 , while for measurements in a shade, the maximum values are up to +5 . In the winter months, the coefficient does not deviate much from the value of 0 . There are several reasons for the very significant diversity compared to the so-called average coefficients determined from the network alignment. A specific application can be considered as the most important one. When measuring large networks (such as the network in the Kingdom of Hanover from 1821 to 1825 measured by K. F. Gauss), where the survey station is elevated (for a better observation of network points often miles away) and usually a large part of the sight is high above the ground (tens of meters). The use of measuring towers was no exception. The temperature at such a height behaves completely differently from the temperature determined by the measurement presented here at a height of up to $2 \mathrm{~m}$ above the ground.

\section{Conclusion}

The task of the whole experiment was to measure real temperatures that may occur in our territory and to critically evaluate what effect refraction may have during the year. The experiment was aimed at engineering surveying, which is usually characterized by a measurement at shorter distances (up to hundreds of metres) and higher accuracy (most often in the order of $\mathrm{mm}$ ). It is clear from the results that there are seasons and times of day that are not suitable for a measurement, as the required accuracy may be exceeded by the effect of the refraction alone. Likewise, the well-known rule was confirmed that during noon to afternoon, the effect of refraction reaches its highest values, and conversely, the best conditions for accurate measurements can be expected at night or very early in the morning. It has a very adverse effect on the measurement results over sunny terrain. A measurement close to the ground on a sunny day is not suitable due to the extreme temperature gradient. However, the steepness of the sight also negatively affects the resulting data. The theoretical ideal would be to measure in a layer where the temperature radiated by the surface and the temperature of the upper atmosphere are equal. This is of course not easy to determine, but the results suggest the height from 1.5 to 1.7 meters above the earth's surface.

A certain danger arising from the observation is the fact that during the night, the atmosphere is not homogeneous, but it is significantly calmer, and the stratification of the atmosphere stabilizes more. 
However, this can result in a systematic effect on the measured data that cannot be recognized during the measurement. The only way to detect such an error would be to re-measure, ideally, on another day (another night) when the atmosphere stratifies differently. However, this is often not possible in practice.

Although this experiment appears to be relatively robust from a measurement point of view, it is not possible to perceive it as a list of corrections to measurements in a given part of the year and at a given time. The benefit should be a concrete idea of the conditions that can be expected in our conditions for measurements near the terrain. Nor can it be considered true that the temperature in the atmosphere is systematically stratified, and that the measurement of the temperature at the survey station describes the temperature over the entire range of the beam path.

In the field of research into the influence of temperature (and refraction in general) on geodetic measurements, several measurements will still need to be made to better understand it. For example, it is not certain at what height above the ground the temperature gradient decreases and the atmosphere becomes more homogenized. For this reason, the calculations were focused only on the height range of the measuring structure.

\section{ACKNOWLEDGEMENTS}

This research was funded by the Grant Agency of CTU in Prague - grant number SGS20/052/OHK1/1T/11 "Optimization of acquisition and processing of $3 \mathrm{D}$ data for purpose of engineering surveying, geodesy in underground spaces and 3D scanning".

\section{REFERENCES}

[1] J. Braun, M. Štroner. Geodetic measurement of longitudinal displacements of the railway bridge.

[2] J. Braun, H. Fladrova, K. Prager. Comparison of different measurement methods of crane runway. In Advances and Trends in Geodesy, Cartography and Geoinformatics II: Proceedings of the 11th International Scientific and Professional Conference on Geodesy, Cartography and Geoinformatics, pp. 3 - 9. 2020. https://doi.org/10.1201/9780429327025-2

[3] J. Bures, D. Bartonek, M. Kalina, O. Svabensky. Security geodetic monitoring of structures. In 7 th International Conference on Cartography and GIS, pp. 874 - 879. Bulgarian Cartographic Association, Bulgaria, 2018.

[4] J. Bureš, L. Bárta, O. Švábenský. Contributions to International Conferences on Engineering Surveying, chap. Influence of External Conditions in Monitoring of Building Structures, pp. 223 - 235. Springer, 2021. https://doi.org/10.1007/978-3-030-51953-7_19

[5] M. Hauf. Technický prưvodce: Geodezie. SNTL Nakladatelství technické literatury, 1982.
[6] L. Hradilek. Refraction in Trigonometric and Three-Dimensional Terrestrial Networks. The Canadian Surveyor 26(1):59 - 70, 1972. https://doi.org/10.1139/tcs-1972-0006

[7] L. Hradilek. Trigonometric levelling and spatial triangulation in mountain regions. Bulletin Géodésique 87(1):33 - 52, 1968. https://doi.org/10.1007/BF02530312

[8] R. Urban, O. Michal. Development deflection of prestressed concrete bridge. In 15th International Multidisciplinary Scientific GeoConference SGEM 2015, pp. 203 - 210. STEF92 Technology Ltd., Sofia, Bulgaria, 2015. https://doi.org/10.5593/SGEM2015/B22/S9.025

[9] Š. Rákay, K. Bartoš, K. Pukanská. The influence of refraction on determination of position of objects under water using total station. In Advances and Trends in Geodesy, Cartography and Geoinformatics, pp. 95 - 100. 2018. https://doi.org/10.1201/9780429505645-16.

[10] T. Křemen. Refrakční koeficient a gaussova hodnota $\mathrm{k}=0,1306$. Geodetický a kartografický obzor 64(8):161 $169,2018$.

[11] C. Hirt, S. Guillaume, A. Wisbar, et al. Monitoring of the refraction coefficient in the lower atmosphere using a controlled setup of simultaneous reciprocal vertical angle measurements. Journal of Geophysical Research: Atmospheres 115(D21), 2010.

[12] T. J. Kukkamaki. Ober die nivellitische Refraktion. Publication of the Finnish Geodetic Institute, Helsinki, 1938.

[13] S. R. Holdahl. Removal of refraction errors in geodetic leveling. In Symposium - International Astronomical Union, vol. 89, pp. 305 - 319. 1979.

[14] P. V. Angus-Leppan. Use of meteorological measurements for computing refractional effects - a review. In Symposium - International Astronomical Union, vol. 89, pp. 165 - 178. 1979. https://doi.org/10.1017/S0074180900065979

[15] D. Gaifillia, V. Pagounis, M. Tsakiri, V. Zacharis. Empirical modelling of refraction error in trigonometric heighting using meteorological parameters. Journal of Geosciences and Geomatics 4(1):8 - 14, 2016.

[16] A. S. Monin, A. M. Obukhov. Basic laws of turbulent mixing in the atmosphere near the ground. Academiia Nauk SSSR, Geofizicheskii institut 24:163 - 187, 1954.

[17] F. K. Brunner. Systematic and random atmospheric refraction effects in geodetic levelling. In Proc. of Second International Symposium on Problems Related to the Redefinition of North American Vertical Geodetic Networks, pp. 691 - 703. 1980.

[18] A. Reiterer. Modeling atmospheric refraction influences by optical turbulences using an image-assisted total station. $Z F V$ - Zeitschrift für Geodäsie, Geoinformation und Landmanagement 137(3):156 - 165, 2012.

[19] B. Böckem, P. Flach, A. Weiss, M. Hennes. Refraction influence analysis and investigations on automated elimination of refraction effects on geodetic measurements. In Proc. IMEKO 2000. 2000. 
[20] H. Ingensand. Concepts and solutions to overcome the refraction problem in terrestrial precision measurement. Geodezija ir Kartografija 34(2):61 - 65, 2008. https://doi.org/10.3846/1392-1541.2008.34.61-65

[21] S. Kyle, S. Robson, L. MacDonald, M. Shortis. Compensating for the effects of refraction in photogrammetric metrology. In Proceedings of 14 th International Workshop on Accelerator Alignment. 2016.

[22] H. Sirůčková. Experimental levelling at the interface of optical environments. Acta Polytechnica 56(2):138 146, 2016. https://doi.org/10.14311/AP.2016.56.0138.

[23] M. Frk, Z. Rozsívalová. Overview, accuracy and sensitivity of temperature sensors in practice.

Elektrorevue 14(4):55-1 - 55-8, 2012.

[24] Návod na použití a kalibrační protokol. Tech. rep., Sensit, Rožnov pod Radhoštěm, 2019.
[25] J. A. Kravcov, J. I. Orlov. Geometričeskaja optika neodnorodnych sred. Moskva: Nauka, 1980.

[26] A. Mikš, J. Pospíšil. Počítačová simulace vlivu atmosféry na geodetická měření. Stavebni obzor: odborný měsíčník 7:220 - 225, 1998.

[27] M. Štroner, J. Pospíšil, T. Křemen, V. Smítka. Geodetická měreni při požárni zkoušce na experimentálním objektu v Mokrsku. České vysoké učení technické v Praze, 2008.

[28] M. Štroner. Metody výpočtu indexu lomu vzduchu. Jemná mechanika a optika 7 -8:224 - 228, 2000.

[29] F. Dvořáček. Interpretation and evaluation of procedures for calculating the group refractive index of air by ciddor and hill. In 18th International Multidisciplinary Scientific GeoConferences SGEM 2018 - Informatics, Geoinformatics and Remote Sensing, vol. 18 , pp. $837-844$. 